\title{
ESTIMATION OF THE SAFE ELECTRICAL LOAD ON SPIRAL BULBS HEATED BY CAPACITORS APPLIED TO MULTIPLE START-UPS OF OPEN GAS GENERATORS
}

\author{
Sergey Goldayev ${ }^{1}$, Sergey Basalayev ${ }^{2, *}$, and Natalya Minkova ${ }^{2}$ \\ ${ }^{1}$ National Research Tomsk Polytechnic University, 634050 Tomsk, Russia \\ ${ }^{2}$ National Research Tomsk State University, 634050 Tomsk, Russia
}

\begin{abstract}
A method was developed for the automated calculation of the safe electrical load on spiral bulbs warmed by capacitors for the multiple start-ups of open gas generators under water. An energy criterion was proposed that would, for spiral bulbs with known dimensions and thermal properties, allow the selection of the type of pulsed power supply providing wire heating required for dibasic solid fuel (DSF) ignition, and maintaining its operative state.
\end{abstract}

\section{Introduction}

For the enabling of multiple start-ups and stops of underwater open gas generators (OG) based on dibasic solid fuels (DSF) [1], a method [2] was proposed, according to which the block fuel 1 is located in an upright position (figure 1).

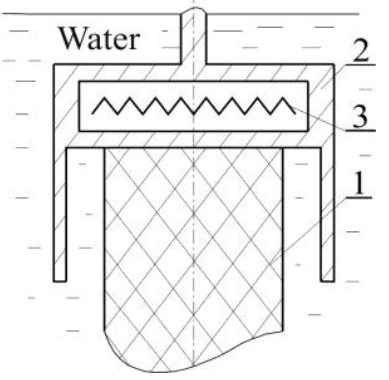

Fig. 1. Arrangement scheme of the block and the heat-resistance glass in the ignition.

Localization of the intended combustion zone at the upper end is achieved by using heat-resistant glass (HG) 2, at the bottom of which a $\mathrm{CH} 3$ alloy with high electrical resistivity is placed (Table 1). The HG covers the sidewalls of the top part of the block with

${ }^{*}$ Corresponding author: tarm@,niipmm.tsu.ru 
liquid that can completely fill the margin formed between the walls and the block.

Table 1. Thermal properties of alloys with high electrical resistance.

\begin{tabular}{|c|c|c|c|c|c|c|}
\hline Alloy & $\begin{array}{c}\rho_{p}, \\
\mathrm{~kg} / \mathrm{m}^{3}\end{array}$ & $\begin{array}{c}c_{p}, \\
\mathrm{~J} / \mathrm{kg} \cdot \mathrm{K}\end{array}$ & $\begin{array}{c}\rho_{0} \cdot 10^{8}, \\
\mathrm{Ohm} \cdot \mathrm{m}\end{array}$ & $\begin{array}{c}T_{p l}, \\
{ }^{\circ} \mathrm{K}\end{array}$ & $\begin{array}{c}\gamma \cdot 10^{4}, \\
1 / \mathrm{K}\end{array}$ & $\begin{array}{c}\left(\rho_{p} c_{p} / \rho_{0}\right) \\
10^{12}\end{array}$ \\
\hline Constantan & 8900 & 410.33 & 49 & 1533 & 0.10 & 7.45 \\
\hline Nickel & 8900 & 468.84 & 7.24 & 1426 & 0.54 & 57.6 \\
\hline Nichrome & 8400 & 460.57 & 110 & 1733 & 4.0 & 3.86 \\
\hline
\end{tabular}

Burning is maintained due to the forced movement down of the $\mathrm{HG}$, and the extinction of DSF occurs after the HG's retraction upward.

An experimental check confirmed [3] that the proposed method of DSF burning in an aquatic environment provides for stable ignition, stable combustion and reliable burning interruption.

\section{The task}

To ensure an emergency start-up of the OG, the energy of a charged capacitor may be used [4], for example, the capacitor included in the construction of the explosive device PC$2000 \mathrm{~m}$ [5]. Its characteristics are shown in Table 2. The stored energy of the capacitor was estimated by the formula $E_{0}=0,5 C_{0} U_{0}^{2}$.

Table 2. Parameters of pulsed power sources.

\begin{tabular}{|c|c|c|c|c|c|}
\hline No. & Brand & $\begin{array}{c}\text { Capacity } \\
C_{0}, \mathrm{uF}\end{array}$ & $\begin{array}{c}\text { Voltage } \\
U_{0}, \mathrm{~V}\end{array}$ & $\begin{array}{c}\text { Energy } \\
E_{0}, \mathrm{~J}\end{array}$ & $\begin{array}{c}\text { Mass, } \\
\mathrm{kg}\end{array}$ \\
\hline 3 & $\mathrm{CSM}-3$ & 4 & 1600 & 5 & 1.6 \\
\hline 4 & $\mathrm{PC}-2000 \mathrm{~m}$ & 50 & 1200 & 35 & 5.2 \\
\hline
\end{tabular}

\section{Approximate methods}

The experience of condenser blasting machine design was used to calculate the heating portion of the ignition of DSF, located near the contact zone of $\mathrm{CH}$ with the bottom of the HG [5]. It was thought that the discharge of a capacitor with the size of $C_{0}$ at the initial voltage of $U_{0}$, occurs to an external circuit having only active resistance. Then the force change of the current over the period of time $t$ is described by the following expression [5]

$$
I=\left(U_{0} / R_{h}\right) \exp \left[-t /\left(R_{h} \cdot C_{0}\right)\right]
$$

where $R_{h}$ is the electrical resistance of the wire.

The heat flux density generated by $\mathrm{CH}$ is represented as a function exponentially decreasing with time [4]

$$
q_{h}=q_{h 0} \exp \left(-2 t / R_{h} \cdot C_{0}\right)
$$

where $q_{h 0}=U_{0}^{2} /\left(R_{h} \cdot S_{h}\right)$ is the maximum heat flux created by $\mathrm{CH}$ at the moment of the 
circuit closing; $S_{h}$ is a heating square, covered by $\mathrm{CH}$.

The approximate method of calculating the characteristics of the ignition described below is based on a criterion - the achievement of the surface of the "temperature flashpoint" sample equal to $T_{b c} \approx 500 \mathrm{~K}$.

For the dependence of the surface temperature of the DSF sample on the time at the accident inert heating stage, an analytical solution with the following form was obtained [4]:

$$
\Theta_{s p}(\tau)=\Theta_{c}+\frac{q}{n \sigma}\left[\frac{a_{2} \Psi_{2}\left(a_{2} \sqrt{z}\right)-a_{1} \Psi_{1}\left(a_{1} \sqrt{z}\right)}{a_{2}-a_{1}}-e^{(-\sigma \tau)}+\frac{\left(a_{2}+a_{1}\right)}{\sqrt{\pi}} \int_{0}^{\tau} \frac{e^{[\sigma(z-\tau)]}}{\sqrt{z}} d z\right],
$$

where similar complexes are marked in such a way for brevity

$$
\Psi_{i}\left(a_{i} \sqrt{\tau}\right)=\exp \left(a_{i} \sqrt{\tau}\right)^{2} \operatorname{erfc}\left(a_{i} \sqrt{\tau}\right) .
$$

Here $\operatorname{erfc}(z)=1-\operatorname{erf}(z)$ is an additional integral of probability.

The dimensionless parameters which are part of (3) are calculated in that way:

$$
\begin{gathered}
a_{1}=n\left(1-\delta_{1}\right) / 2, a_{2}=n\left(1+\delta_{1}\right) / 2, \quad \delta_{1}=\sqrt{1-4 n \mathrm{Bi}_{c}}, 1-4 n \mathrm{Bi}_{c}>0 \\
\sigma=\frac{2 t_{r}}{R_{h} C_{0}} ; \mathrm{Bi}_{c}=\frac{\alpha_{e f} l_{m}}{\lambda_{k}}, q=\frac{q_{h} l_{m}}{\lambda_{k} T_{m}}, \quad n=\frac{c_{h} \cdot \rho_{h} \cdot d_{h}+c_{s} \cdot \rho_{s} \cdot d_{s}}{c_{k} \cdot \rho_{k} \cdot l_{m}} .
\end{gathered}
$$

Here $t_{r}=2.3 R_{e l} \cdot C_{0}$ is the time of discharge of the capacitor [6]; physical properties of DSF, spiral bulbs and heat-resistant glass: $\rho_{k}$ is density, $\mathrm{kg} / \mathrm{m}^{3} ; c_{k}$ is the specific heat capacity of the mass, $\mathrm{J} /(\mathrm{kg} \cdot \mathrm{K}) ; \lambda_{k}, a_{k}$ are thermal conductivity coefficients, $\mathrm{V} / \mathrm{m} \cdot \mathrm{K}$ and thermal diffusivity, $\mathrm{m}^{2} / \mathrm{s} ; c_{h}$ are the specific heat capacity of the mass, $\rho_{h}$ is density and $d_{h}$ is the diameter of the wire; $c_{s}$ is the specific heat capacity of the mass, $\rho_{s}$ is density and $\delta_{s}$ is the thickness of the HG's bottom; $\alpha_{e f}$ is the effective heat transfer coefficient.

The scale coordinates and density of the heat flux are:

$$
l_{m}=\sqrt{a_{k} t_{r}}, q_{m}=\lambda_{k} \cdot T_{0} / l_{m} .
$$

The calculation of the probability integral was carried out according to the interpolation formula [6] which has one coefficient

$$
\operatorname{erf}(z)=\sqrt{1-\exp \left(-1.26 z^{2}\right)}
$$

The costs of heating the bottom part of the HG are calculated with the help of the $n$ parameter in the DSF ignition scheme shown in figure 1.

$$
q_{H C}=\frac{1}{t_{r}} \int_{0}^{t_{r}} q_{H} d t=\frac{U_{0}^{2}}{4.6 R_{h} \cdot S_{h}} .
$$


Let us note that $q_{H C}$ indirectly depends on $C_{0}$ through $t_{r}$ and affects the parameter $\sigma$, reducing it with the increasing of $C_{0}$. Another option in data processing is the use of the initial value of the specific electrical energy equal to the ratio of $A_{0}=E_{0} / S_{h}$.

\section{The results of the ignition time}

An analysis was conducted for $\mathrm{CH}$ from nichrome wires of different diameters. Table 3 shows the calculated data of $t_{z}$ depending on $A_{0}$ for the N type of DSF.

Table 3. Ignition time at varying the heat load on $\mathrm{CH}$ in the presence of the screen.

\begin{tabular}{|l|c|c|c|c|c|c|}
\hline \multicolumn{2}{|c|}{$A_{0}, \mathrm{~mJ} / \mathrm{m}^{2}$} & 0.25 & 0.50 & 0.75 & 1.0 & 1.25 \\
\hline \multirow{2}{*}{$1)$} & $\infty$ & 0.2 & 0.14 & 0.10 & 0.065 \\
\cline { 3 - 7 } 2$)$ & \multirow{2}{*}{$t_{z}, \mathrm{~ms}$} & 0.3 & 0.13 & 0.095 & 0.086 & 0.85 \\
\cline { 3 - 7 } & 0.3 & 0.075 & 0.03 & 0.02 & 0.018 \\
\hline
\end{tabular}

The length of the wire was $140 \mathrm{~mm}$ and the diameter for variants 1 and 2 was $0.1 \mathrm{~mm}$, and for variant 3 was $0.25 \mathrm{~mm}$. For fixed $U_{0}=1600 \mathrm{~V}$ capacitance the values ranged from 4 to $40 \mathrm{uF}$. The thermal load $A_{0}$ varied from 0.06 to $0.69 \mathrm{~mJ} / \mathrm{m}^{2}$, and $t_{z}$ decreased from 9.1 to $8.3 \mathrm{~ms}$.

Installing $\mathrm{HG}$ onto the end part of the block leads to the appearance of a screen between the surface of DSF and $\mathrm{CH}$ of $1 \mathrm{~mm}$ thickness. The varying of $U_{0}$ from 950 to $2000 \mathrm{~V}$ increased $E_{0}$ from 22.6 to $100 \mathrm{~J}$, the corresponding thermal load increased from 0.3 to 1.34 $\mathrm{mJ} / \mathrm{m}^{2}$, and $t_{z}$ decreased from 347 to $60 \mathrm{~ms}$ (variant 1). During the discharge the surface temperature of the block reached only $396 \mathrm{~K}$ when $C_{0}=5 \mathrm{uF}$ and $U_{0}=1600 \mathrm{~V}$.

In the next series of calculations $C_{0}$ changed from 10 to $80 \mathrm{uF}$, and the voltage was $U_{0}=$ 1600. The results are shown in the form of the 2 nd variant. From the structure of dependence (2) for the heat flux density generated by $\mathrm{CH}$ it follows that its amplitude is defined by the initial voltage $U_{0}$. The capacitance value affects the development of the process of heating the sample in time - for large $C_{0}$ ( $\sigma$ parameter is less) the temperature rise is slower and the ignition time increases.

The change in $d_{p}$ is affected through the $n$ and $q_{H C}$ parameters. A wire 2.5 times as thick was used in the 3 rd variant and as a result, the $n$ parameter value became 2.5 times larger. However, $R_{h} \sim 1 / d_{p}^{2}$ and therefore $q_{H C}$ increased to 6.25, which resulted in a decrease of $t_{z}$.

Thus, the analysis showed that in the presence of a thin steel screen between $\mathrm{CH}$ and the end surface of a block from DSF, sources that allow the production of an energy density of more than $30 \mathrm{~mJ} / \mathrm{m}^{2}$ in the section of DSF heating are necessary for the realization of this process. In particular, a PC $-2000 \mathrm{~m}$ explosive device can be used.

\section{Estimation of the safe electrical load on spiral bulbs heated by capacitors}

To ensure re-ignition of the block of the same $\mathrm{CH}$ it is necessary that its electrical resistance changes little and that contact with the connecting wires is maintained.

The conductor may break after its heating to a temperature comparable to the melting temperature $T_{p l}$ of the corresponding metal with high resistivity shown in Table 1 . The results of such an analysis for the variant of $\mathrm{CH}$ heating from an autonomous power supply of direct currents are shown in the work [7]. 
Within the thermo-technical approach of evaluating the load on the conductors of nichrome or another alloy, the maximum current strength is determined that can be passed through the wire heater surrounded by air, so that the maximum temperature does not exceed $1273 \mathrm{~K}$ [8].

In another source [9], it is necessary to calculate the strength of the current going through thin nichrome wire of $0.1 \mathrm{~mm}$ in diameter and $2 \mathrm{~m}$ in length, placed horizontally in the air, having a temperature of $293 \mathrm{~K}$, at which its destruction will occur, if it is known that nichrome has $T_{p l}=1733 \mathrm{~K}$.

There is such a task in [10]. An electric detonator in the form of a cylinder of $0.1 \mathrm{~mm}$ in diameter and $5 \mathrm{~mm}$ in length is in air whose temperature is $T_{0}=303 \mathrm{~K}$, the intensity of cooling heating wire is characterized by the heat transfer coefficient $\left.\alpha=10 \mathrm{~W} /\left(\mathrm{m}^{2} \cdot \mathrm{K}\right)\right)$. The thermal properties of the detonator are: thermal conductivity $\lambda_{h}=20 \mathrm{~W} /(\mathrm{m} \cdot \mathrm{K}), a_{h}=5 \cdot 10^{-}$ ${ }^{5} \mathrm{~m}^{2} / \mathrm{s}$, the melting temperature of the detonator's metal is $1173 \mathrm{~K}$, and the electrical resistance $R_{h}=0.2 \mathrm{Ohm}$. The task is to determine the time after which the detonator would explode when passing through it a constant current of $3 \mathrm{~A}$, neglecting the radiation and escape of the heat to the attachment at the ends of the detonator. The value of $t=7.62 \mathrm{~ms}$ is given in the answer.

Let us add to the results of the DSF ignition analysis for spiral bulbs heated by capacitors an estimation of the time required to reach the temperature limit $T_{p l}$.

Let us sum up the formulations given in [7] due to the reducing current (1).

Let us write the heat balance of the area of wire based on the energy conservation equation.

When an electrical current passes through a conductor of cylindrical shape of $d_{p}$ in diameter and $l_{p}$ in length, heat is generated which can be calculated by the formula of Joule [9]:

$$
Q=I^{2} R_{p}=U_{0}^{2} \cdot \exp \left(-2 t / R_{p} C_{0}\right) \sigma_{p} /\left(\rho_{e l} l_{p}\right)
$$

where $\sigma_{p}$ is the cross-sectional square of the conductor.

Cooling of the conductor is carried out by free convection and radiation, and c can be taken into account by an appropriate heat transfer coefficient [8]. Let us use the effective value of $\alpha$ equal to $2000 \mathrm{~W} /\left(\mathrm{m}^{2} \mathrm{~K}\right)[11]$, which corresponds to the intensity of the heat exchange between wire of nickel alloy and chromium, heated when passing through an electrical current and DSF embedded in the surface layer. Estimation of the Bio number $\mathrm{Bi}=\alpha d_{p} / 2 \lambda$ shows that for thick wires in the task it is $\mathrm{Bi}=\alpha d_{p} / 2 \lambda=2 \cdot 10^{3} \cdot 0.5 \cdot 10^{-3} / 2 \cdot 11.6=0.043$. Consequently the thermally thin body model is applicable [9].

The heat balance equation for the wire has the following form

$$
c_{p} \rho_{p} V_{p} d T_{p} / d t=Q-\alpha\left(T_{p}-T_{w}\right) S_{p}
$$

where $c_{p}$ is the specific heat capacity of the mass of the conductor; $\rho_{p}$ is its density; $V_{p} S_{p}$ is the volume and the square of the surface of the conductor.

Having substituted into the differential equation (6) the expression for heat evolution (5), we obtain a linear inhomogeneous ordinary first-order differential equation:

$$
d T_{p} / d t+A\left(T_{p}-T_{w}\right)=B \exp (-D t)
$$

where 


$$
A=\frac{\alpha S_{p}}{\left(c_{p} \cdot \rho_{p} \cdot V_{p}\right)} ; \quad B=\frac{U_{0}^{2}}{\left(c_{p} \cdot \rho_{p} \cdot V_{p} \cdot R_{e l}\right)} ; D=\frac{2}{R_{p} \cdot C_{0}}
$$

The temperature of the wire is equal to the temperature of the wall of the heat-resistant glass at the initial moment of time: at $t=0 T_{p}=T_{w}$.

Using the expression for the general integral (7) from [12] and determining the integration constant using initial conditions, we obtain

$$
T_{p}=T_{w}+B[\exp (-D t)-\exp (-A t)] /(A-D) .
$$

The described algorithm for calculating the desired temperature was employed using a PC.

The following results were obtained in the course of the parametric analysis. The temperature of the nichrome wire $d_{p}=0.2 \cdot 10^{-3} \mathrm{~m}, l_{p}=0.12 \mathrm{~m}$ in length, reached a maximum value $T_{p}=650 \mathrm{~K}$ by the time moment $t=0.08 \mathrm{~ms}$ after using the capacitor subversive machine CSM-3 with $U_{0}=1600 \mathrm{~V}$ and the capacity $C_{0}=4 \mathrm{uF}$. A twofold reduction $\mathrm{f} d_{p}$ leaving the other parameters unchanged led to the wire after the heating time $t=0.24 \mathrm{~ms}$ reaching the maximum temperature of $1697 \mathrm{~K}$, which exceeds the melting temperature of nichrome. Using a pulsed source of PC-2000m with higher energy $\left(E_{0}=50\right.$ $\mathrm{J})$ contributes to the intense increase in the temperature of the wire, which at the time $t=$ $0.06 \mathrm{~ms}$ had already been exceeding $T_{p l}$.

Analysis of the obtained results showed that in cases when $E_{0}$ is less than the energy required to heat the wire to the melting temperature $E_{p}=c_{p} \rho_{p} V_{p}\left(T_{p l}-T_{w}\right)$, then the wire maintains a functional state.

For example, heating the wire of $d_{p}=0.2 \mathrm{~mm}$ and $l_{p}=0.2 \mathrm{~m}$ up to $T_{p l}$ requires $34.3 \mathrm{~J}$ of energy. The PC-2000m pulsed source has $36.0 \mathrm{~J}$ of energy. By the time moment $t=0.51$ $\mathrm{ms}$ the temperature of the wire reaches $1693 \mathrm{~K}$. The choice of wire of $d_{p}=0.5 \mathrm{~mm}$ and the previous length requires $128.5 \mathrm{~J}$ of energy to heat it to the temperature $T_{p l}$. The use of a PC$2000 \mathrm{~m}$ pulsed source allows heating of the wire to $694.6 \mathrm{~K}$.

Another option for $\mathrm{CH}$ conservation in the functional state is to switch it off after its heating, for example, up to $1000 \mathrm{~K}$. In practice, this can be realized with the aid of a technical solution [13], where the shunt resistor is set parallel to the heating wire and a fuse strip is placed successively with this juncture. When using an electro-initiator via a current impulse of an amplitude from $2 \mathrm{~A}$ and duration of $30 \mathrm{~ms}$ there occurs a fail-proof ignition of the working charge with a probability of not less than 0.999 , and the subsequent failproof shutdown of the electro-initiator with the same probability.

\section{Conclusion}

A method was developed for the automated calculation of the safe electrical load on spiral bulbs heated by capacitors for multiple start-ups of an open underwater gas generator. An energy criterion has been proposed which allows the selection of a type of pulsed power supply that enables the heating of wire required for DSF ignition, and maintaining the functional state of spiral bulbs with known dimensions and thermal properties. 


\section{Acknowledgments}

The reported study was funded by RFBR according to the research project No. 16-03-00630a.

\section{References}

1. V.D. Barsukov, S.V. Goldaev, Teoriya, eksperiment, tehnicheskie predlozheniya (Izdvo Tom. un-ta, Tomsk, 2003) [in Russian]

2. V.D Barsukov, S.V Goldaev, N.P, Minkova, S.N. Polenchyuk, Patent 2345277 RF Sposob szhiganiya unitarnogo tverdogo topliva v zhidkoy srede, Opebl. v BI No.3 ot 27.01.2009

3. V.D. Barsukov, S.A. Basalaev, S.V. Goldaev, N.P. Minkova, Khim. Fiz. Mezoskopiya 17, 2 (2015)

4. V.D. Barsukov, S.V. Goldaev, N.P. Minkova, N.A. Babushkin, Vestnik TSU: Matematika i mehanica 3 (2015) [in Russian]

5. M.M. Graevskiy, Spravochnik po elektricheskomu vzryvaniyu zaryadov (Randevu, Moscow, 2000) [in Russian]

6. A.N. Reznikov, L.A. Reznikov, Teplovie protsessy $v$ tehnologicheskih sistemah (Mashinostroenie, Moscow, 1990) [in Russian]

7. S.V. Goldaev, N.A. Babushkin, S.A. Basalaev, EPJ Web Conf. 23, Article Number 01014 (2015)

8. K.D. Voskresenskiy, Sbornik raschetov $i$ zadach po teploperedache (Gosud. energetich. izd-vo, Leningrad, 1959) [in Russian]

9. F.F. Tsvetkov, R.V. Kerimov, V.I. Velichko, Zadachnik po teplomassoobmenu (Izdatelskiy dom MEI, Moscow, 2008) [in Russian]

10. F. Kreit, U. Black, Osnovy teploperedachi (Mir, Moscow, 1983) [in Russian]

11. E.B. Volkov, T.A. Syritsyn, G.Y. Mazing, Statika i dinamika raketnyh dvigatelnyh ustanovok (Mashinostroenie, Moscow, 1978) [in Russian]

12. I.N. Bronschtein, K.A. Semendyaev, Spravochnik po matematike (Nauka, Moscow, 1986) [in Russian]

13. P.A. Voronov, O.L. Ignatov, Y. M. Sidorkin, A.V. Sokolov, A.A. Uskov, Patent 2156946 RF Elektroinitsiator s samootklyucheniem ot istochnika toka MKI 7 F42 b 3/12 /- Zayavl 12.02. 1999 Opubl. 27.09.2000 [in Russian] 